\title{
Psychological adjustment and quality of life in children and adolescents following open-heart surgery for congenital heart disease: a systematic review

\author{
Beatrice Latal ${ }^{1}$, Susanne Helfricht ${ }^{1}$, Joachim E Fischer ${ }^{2}$, Urs Bauersfeld ${ }^{3}$ and \\ Markus A Landolt*4
}

Address: ${ }^{1}$ University Children's Hospital Zurich, Child Development Centre, Steinwiesstrasse 75, 8032 Zurich, Switzerland, ${ }^{2}$ Heidelberg University, Mannheim Medical Faculty, Institute of Public Health, Social and Preventive Medicine, 68072 Mannheim, Germany, ${ }^{3}$ University Children's Hospital Zurich, Department of Pediatric Cardiology, Steinwiesstrasse 75, 8032 Zurich, Switzerland and ${ }^{4}$ University Children's Hospital Zurich, Department of Psychosomatics and Psychiatry, Steinwiesstrasse 75, 8032 Zurich, Switzerland

Email: Beatrice Latal - bea.latal@kispi.uzh.ch; Susanne Helfricht - susanne.helfricht@gmx.net; Joachim E Fischer - jfischer@medma.uniheidelberg.de; Urs Bauersfeld - urs.bauersfeld@kispi.uzh.ch; Markus A Landolt* - markus.landolt@kispi.uzh.ch

* Corresponding author

Published: 22 January 2009

BMC Pediatrics 2009, 9:6 doi:10.1186/147I-2431-9-6

This article is available from: http://www.biomedcentral.com/|47/-243 I/9/6

(c) 2009 Latal et al; licensee BioMed Central Ltd.

This is an Open Access article distributed under the terms of the Creative Commons Attribution License (http://creativecommons.org/licenses/by/2.0), which permits unrestricted use, distribution, and reproduction in any medium, provided the original work is properly cited.
Received: 28 May 2008

Accepted: 22 January 2009

\begin{abstract}
Background: Children with congenital heart defects (CHD) requiring open-heart surgery are a group at high risk for health-related sequelae. Little consensus exists regarding their long-term psychological adjustment (PA) and health-related quality of life (QoL). Thus, we conducted a systematic review to determine the current knowledge on long-term outcome in this population.

Methods: We included randomized controlled trials, case control, or cohort studies published between 1990-2008 evaluating self- and proxy-reported PA and QoL in patients aged between two and 17 years with a follow-up of at least two years after open heart surgery for CHD.

Results: Twenty-three studies assessing psychological parameters and 12 studies assessing QoL were included. Methodological quality of the studies varied greatly with most studies showing a moderate quality. Results were as follows: (a) A considerable proportion of children experienced psychological maladjustment according to their parents; (b) studies on self-reported PA indicate a good outcome; (c) the studies on QoL suggest an impaired QoL for some children in particular for those with more severe cardiac disease; (d) parental reports of psychological maladjustment were related to severity of CHD and developmental delay.
\end{abstract}

Conclusion: A significant proportion of survivors of open-heart surgery for CHD are at risk for psychological maladjustment and impaired QoL. Future research needs to focus on self-reports, QoL data and adolescents.

\section{Background}

Congenital heart disease (CHD) occurs in 4-12 per 1,000 live births $[1,2]$. More than one third of the affected children are born with "critical heart disease" denoting mal- formations, which acutely threaten life and necessitate palliative or corrective surgery in early life [3]. Advances in surgical and postoperative support techniques have significantly reduced the mortality and have lead to acceptable 
mid- and long-term cardiac outcome even for children with complex CHD, premature or low-birth-weight children [4-8]. Various risk factors for long-term morbidity have been identified. Particularly, cardiopulmonary bypass surgery is associated with inflammatory responses, renal, myocardial, and neurological injury [9] and may consequently lead to neurodevelopmental impairments $[10,11]$. While open-heart surgery can correct or palliate $\mathrm{CHD}$, it also represents the challenge of psychologically adjusting to the surgical event and associated side effects for the child and the parents. Moreover, the question arises as to how quality of life in these patients is affected by the surgical event.

There is an increasing body of literature addressing these questions. Many studies have examined neuropsychological functioning, behavior and quality of life in children and parents. However, methodological shortcomings make it difficult to compare studies. They vary greatly in study design, inclusion criteria, assessment of risk factors, duration of follow-up, attrition and in particular in outcome measures. Thus, a systematic review of the existing literature is needed to summarize the evidence on psychological outcome and quality of life and the pertinent risk factors.

To facilitate the understanding of this review, the relevant terminology is briefly introduced: The assessment of $p s y$ chological adjustment incorporates a range of outcome measures including behavioral, emotional or psychosocial constructs. A common approach differentiates between internalizing and externalizing behavior difficulties [12]. The former are characterised by symptoms of anxiety, depression, and withdrawal, while the latter include delinquent, aggressive, and show off behavior.

Quality of life (QoL) is a multidimensional construct integrating an individual's subjective perceptions of physical, social, emotional and cognitive functioning [13]. In the context of patient populations this is referred to as healthrelated quality of life. Traditionally, QoL in cardiac patients has been estimated by objective indices related to health outcomes such as cardiopulmonary exercise capacity [14], exercise tolerance [15], or the New York Heart Association classification. However, meanwhile there is a general agreement that these indices alone do not suffice to reflect QoL in cardiac patients in all its facets [16].

Psychological adjustment and QoL can be assessed by means of self- or proxy-reports. Generic as well as diseasespecific assessment instruments exist. The former are used with any patient population independent of their disease, while the latter assess disease-specific issues. Some instruments combine generic with disease-specific items.
This review aims to systematically assess studies on psychological adjustment and QoL in children and adolescents with CHD undergoing cardiopulmonary bypass surgery. Also, associations between medical, individual and familial risk factors and the long-term outcome were evaluated.

\section{Methods \\ Search strategy and selection criteria}

For the period between January 1990 and July 2008 a literature search was conducted via EMBASE, MEDLINE, CINAHL, and PsycInfo to identify eligible studies and review articles. We chose this rather short period to reduce the variance in observed outcomes due to time-dependent advances in surgical techniques. Additionally, databases of dissertations were searched for (ProQest, NDLTD). Great effort was spent to identify the best search strategy for the respective databases aiming at a good ratio of overall hits and eligible studies. An initial search used the identifiers congenital heart disease, congenital heart defect*, the main diagnostic categories of CHD known to require cardiopulmonary bypass surgery (e.g., tetralogy of Fallot, transposition of the great arteries, hypoplastic- left heart syndrome, etc.), $p^{*}$ ediatrics, child ${ }^{*}$, adolescent ${ }^{*}$, adolescence, open-heart surgery, cardiac surgery, cardiopulmonary bypass surgery, heart-lung machine, arterial switch, atrial switch, Mustard, Senning, Norwood, Fontan, circulatory arrest, hypothermia, low flow, full flow, behavio ${ }^{*} r$, psychological, psychosocial, psychiatric, psychopathology, mental health, health, quality of life, health-related quality of life, adjustment, adaptation, emotional, development*, neurodevelopment* The Boolean operator "and" was used to combine identifiers for patient population, intervention, and outcome. The operator "or" was used to combine identifiers within those search areas. Adjustments in search strategies were made for CINAHL and PsycInfo as the initial search strategy was too specific and resulted in few hits only. Overall, the electronic search resulted in 732 hits. Reference lists of relevant studies and reviews were examined to identify other pertinent articles. Furthermore, investigators from the field were contacted to enquire about unpublished data. One reviewer $(\mathrm{SH})$ pre-selected 84 articles according to the information obtained from titles or abstracts. Two independent reviewers (BL, MAL) blinded to the origin of the articles checked the full texts of these articles for inclusion according to a standardized predefined checklist. Inclusion and exclusion criteria are presented in Figure 1. Since there were few studies where all patients were operated with open-heart surgery, we included those in which the majority of patients (>50\%) were operated with open-heart surgery. The follow-up period of at least 2 years was chosen to exclude the effect of acute psychological distress. In addition, we only focused on a pediatric population and thus included studies in which patients were on average younger than 17 years at the time of 


\begin{tabular}{|c|c|c|}
\hline & Inclusion criteria & Exclusion criteria \\
\hline Diagnosis & Congenital heart defects & $\begin{array}{l}\text { Acquired heart defects; } \\
\text { Exclusive assessment of samples with genetic } \\
\text { disorder (i.e., } 22 \text { q11 deletion, Trisomy } 21 \text { ); } \\
\text { Exclusive assessment of samples with specific } \\
\text { characteristics (i.e., postoperative } \\
\text { encephalopathy) }\end{array}$ \\
\hline Intervention & $\begin{array}{l}\text { Cardiopulmonary bypass surgery in }>50 \% \text { of } \\
\text { the sample }\end{array}$ & $\begin{array}{l}\text { Exclusive assessment of heart or heart-lung } \\
\text { transplants }\end{array}$ \\
\hline $\begin{array}{l}\text { Mean follow up interval } \\
\text { since surgery }\end{array}$ & $\geq 2$ years of age & $<2$ years of age \\
\hline Mean age at follow up & $<17$ years of age & $>17$ years of age \\
\hline Outcome & Quantitative self-, proxy-, examiner's reports & Qualitative reports \\
\hline - Psychological assessment & Psychoemotional, behavioral dimensions & Neuromotor development, cognitive dimensions \\
\hline - Quality of life & Multidimensional assessment & $\begin{array}{l}\text { Unidimensional indices traditionally used to } \\
\text { assess QoL: e.g., physical outcome (i.e., exercise } \\
\text { tolerance, functional status), school attendance, } \\
\text { or level of activity }\end{array}$ \\
\hline Quality of reporting & $\begin{array}{l}\text { Surgery/ follow up data presented, inferable or } \\
\text { provided by authors upon request }\end{array}$ & $\begin{array}{l}\text { Surgery/ follow up data available does not enable } \\
\text { full consideration of inclusion and exclusion } \\
\text { criteria }\end{array}$ \\
\hline Data analyses & $\begin{array}{l}\text { Basic descriptive statistics (e.g., mean, } \\
\text { median, SD); if psychiatric diagnoses are } \\
\text { assessed presentation of percentages suffice }\end{array}$ & No basic descriptive statistics \\
\hline
\end{tabular}

\section{Figure I}

Overview of inclusion and exclusion criteria.

assessment. The other inclusion criteria were created to enable a meaningful conclusion regarding main effects and risk factors for PA and QoL. In case of missing information, corresponding authors were contacted. Accordingly, 23 studies on psychological adjustment and 12 studies assessing QoL were included. We did not identify any unpublished data eligible for inclusion.

\section{Quality assessment}

Methodological quality of the included studies was rated by the two blinded reviewers (BL, MAL). A standardized checklist with criteria relating to recruitment, study design, operationalisation of outcome, and statistical analyses was used. Each criterion was rated on a two- or three-step scale indicating the degree of fulfillment with the respective criterion. The checklist is presented in Figure 2. Overall scores ranged from 0 to 11 points with higher scores indicating a better study quality. Interrater reliability was excellent (Cohen's kappa $=0.91$ ). In case of disagreement between the two reviewers, consensus was achieved. In addition, three quality groups were formed: good (score 9-11), moderate (score 6-8) and poor (score $0-5)$ quality.

\section{Data extraction and synthesis}

Two independent reviewers (BL, MAL) extracted data on relevant outcomes, characteristics of study design, sample, and surgical technique. Study samples differed significantly with regard to severity of heart defect, age at time of surgery, number of operations, postoperative course, or age at follow up. Moreover, as summarized in Table 1, the operationalization of psychological outcome and QoL varied greatly as different constructs such as behavior, self esteem or mental health had been evaluated. Heterogeneity of assessment methods and differing presentation of the results did not permit formal meta-analysis. Therefore, 


\begin{tabular}{|c|c|c|c|c|}
\hline \multirow[t]{3}{*}{1 Recruitment } & a) Avoidance of selection bias & $\begin{array}{l}\text { - All patients from data base included, } \\
\text { or random patient selection }\end{array}$ & $\begin{array}{l}\text { Convenience sample (e.g., inclusion of } \\
\text { patients attending regular medical check } \\
\text { ups only) }\end{array}$ & $\begin{array}{l}\text { Selection method not } \\
\text { reported }\end{array}$ \\
\hline & $\begin{array}{l}\text { b) Avoidance of non-response } \\
\text { bias }\end{array}$ & $\begin{array}{l}\text { - Response rate: }>85 \% \text {; no } \\
\text { differences between responders } \\
\text { and non-responders }\end{array}$ & $\begin{array}{l}85 \%>\text { response rate }>65 \% \text {; and } / \text { or } \\
\text { significant differences between } \\
\text { responders and non-responders }\end{array}$ & $\begin{array}{l}\text { Response rate }<65 \% \text {; or } \\
\text { response rate not reported }\end{array}$ \\
\hline & & Deduct 1 point, if description of non-r & responders is missing & \\
\hline \multirow[t]{3}{*}{2 Design } & a) Course of measurement & & $\begin{array}{l}\text { Prospective design (i.e., prospective } \\
\text { assessment of outcome parameters, } \\
\text { prospective collection of medical data } \\
\text { does not suffice) }\end{array}$ & - Retrospective design \\
\hline & b) Informants & & - Multi-informants (i.e., self and proxy) & - Single-informants \\
\hline & c) Type of controls & & $\begin{array}{l}\text { - Healthy or chronically ill controls, and/ } \\
\text { or reference or normative samples }\end{array}$ & $\begin{array}{l}\text { Cut off values; no statistical } \\
\text { group comparison }\end{array}$ \\
\hline \multicolumn{2}{|c|}{3 Outcome assessment } & $\begin{array}{l}\text { - Standardized, validated } \\
\text { instruments (CBCL, YSR) }\end{array}$ & $\begin{array}{l}\text { - Non-validated instruments, yet psycho- } \\
\text { metric properties reported }\end{array}$ & $\begin{array}{l}\text { Non-validated instruments, no } \\
\text { psychometric evaluation }\end{array}$ \\
\hline \multicolumn{2}{|c|}{4 Confounding and effect modification } & $\begin{array}{l}\text { - statistical adjustment for basic } \\
\text { medical and sociodemographic } \\
\text { data (e.g., by means of multiple } \\
\text { regression, analysis of covariance) }\end{array}$ & $\begin{array}{l}\text { basic medical and/ or socio- } \\
\text { demographic data were considered } \\
\text { (i.e., descriptive estimates ) }\end{array}$ & $\begin{array}{l}\text { no information about } \\
\text { medical or sociodemographic } \\
\text { data }\end{array}$ \\
\hline
\end{tabular}

Figure 2

Overview of methodological quality rating criteria for included studies.

findings are summarized in a narrative way. An overview of study characteristics, methodological quality ratings, and study results is presented in Additional file 1 and 2 [see Additional file 1 and 2]. The mean (standard deviations; range) quality rating scores for studies on PA was 7.04 (1.33; 4-10); for studies on QoL it was $6.54(1.45 ; 5-$ $9)$. Overall, most studies reporting on psychological adjustment and QoL were of moderate quality (78\%; 55\% respectively); two studies in each area of research were rated as high quality studies (9\%; 18\% respectively) [see Additional file 1 and 2].

\section{Results}

\section{Psychological adjustment}

\section{Incidence of clinically significant maladjustment}

Two studies examined psychiatric diagnoses according to the DSM-IV [17] by means of respondent-based semistructured interviews: Rates of psychiatric disorders for children with surgically corrected transposition of the great arteries [18] and children with severe cyanotic defects after surgery [19] amounted to $19 \%$ and $46 \%$, respectively. However, in children with transposition of the great arteries [18], the corrective surgery was performed with the Senning or Mustard procedure, which does not achieve a complete repair of the underlying heart defect.

Almost all studies examined behavior according to parental reports assessed by the Child Behavior Checklist [12]. Reported rates of maladjustment ranged from $5 \%$ to $41 \%$. Except for one study in which children with cyanotic-corrected heart disease (transposition of the great arteries, tetralogy of Fallot) had low maladjustment rates [20], all rates were significantly higher than those reported for either a normative group or another type of control group (i.e., siblings or healthy controls).

Two studies published results on teacher reports of child maladjustment. Compared to parents, deviant behavior was less frequently reported by teachers, with rates ranging from $4 \%$ [21] to $14 \%$ [22]. These rates were not significantly different from controls.

\section{Proxy-reported psychological functioning}

Besides assessing the incidence of clinically significant maladjustment another approach is to assess mean levels of postoperative psychological functioning across samples. The majority of studies reported on proxy-reported 
Table I: Overview of questionnaires and interviews applied in the reviewed studies to assess psychological adjustment and quality of life

\begin{tabular}{|c|c|}
\hline Diagnostic instruments & Studies (Reference numbers) \\
\hline \multicolumn{2}{|l|}{ Psychological adjustment - semi-structured interviews } \\
\hline Child Assessment Schedule (CAS) & {$[19]$} \\
\hline Child Behavior Problems Interview (CBPI) & {$[18]$} \\
\hline \multicolumn{2}{|l|}{ Psychological adjustment - proxy-report measures } \\
\hline Child Behavior Checklist (CBCL) & {$[19-22,24-33,35,36,38,39]$} \\
\hline Teacher's Report Form (TRF) & {$[21,22,33]$} \\
\hline Vineland Adaptive Behavior Scales (VABS) & {$[29,40]$} \\
\hline \multicolumn{2}{|l|}{ Psychological adjustment - self-report measures } \\
\hline Child Depression Inventory (CDI) & {$[23,36]$} \\
\hline Children's Manifest Anxiety Scale-revised (CMAS-R) & {$[23]$} \\
\hline Fear Survey Schedule for Children-revised (FSSC-R) & {$[23]$} \\
\hline Frankfurt Scales of Self Concept (FSKS, German) & {$[34]$} \\
\hline High School Personality Questionnaire (HSPQ) & {$[34]$} \\
\hline I Think I Am Scale (ITIAS) & {$[18]$} \\
\hline Self Perception Profile for Children & [36] \\
\hline State-Trait Anxiety Inventory (STAI) & {$[34,36]$} \\
\hline Youth Self Report (YSR) & {$[27,34,35]$} \\
\hline \multicolumn{2}{|l|}{ Quality of life } \\
\hline Child Health Questionnaire, parent form (CHQ-PF) & {$[41,43,46]$} \\
\hline Child Health Questionnaire, child form (CHQ-CF) & {$[44]$} \\
\hline Inventory for the Assessment of the Quality of life in Children and Adolescents (IQLC) & {$[24]$} \\
\hline Lindström Model of Quality of Life (LMQL) & {$[42]$} \\
\hline LQ-KID and LQ-KID-E & [49] \\
\hline Pediatric Quality of life Inventory (PedsQL) & {$[28,47]$} \\
\hline Pediatric Cardiac Quality of Life Inventory (PCQLI) & {$[50]$} \\
\hline TNO-AZL Child Quality of Life Questionnaire (TACQOL) & {$[45,48]$} \\
\hline
\end{tabular}

psychological functioning in children with CHD. Parentreported overall behavioral functioning was consistently more affected than that of normative samples or control groups. Psychological difficulties consisted predominantly of internalizing symptoms [21,23-27] Three studies also observed significantly more externalizing symptoms; one study for children with surgically corrected transposition of the great arteries compared to norms [24]; one for children with hypoplastic left heart syndrome compared to children with transposition of the great arteries [28] and the third for children with ventricular septal defect compared to children with atrial septal defect [27]. Except for one [28] all of the above studies were of moderate methodological quality.

In contrast, four studies did not detect any significant differences in proxy-reported psychological functioning [22,29-31]. Of these, one study had received a high-quality methodological rating [31]. Interestingly, one study with a moderate quality rating reported a better behavioral outcome in children with d-transposition of the great arteries after arterial switch operation [32] compared to controls. However, these children were only two years of age at the time of assessment.
Proxy-reports by teachers did not reveal any significant differences in behavior between children with operated heart defects and controls $[21,22]$ except for one study, which reported more behavioral difficulties in operated children compared to controls [33].

\section{Self-reported psychological functioning}

Seven studies evaluated self-reported psychological functioning. While three studies did not observe significant differences with regard to overall fear and anxiety [23], self-esteem [18] or overall behavioral difficulties [34], one study found significantly more behavioral difficulties in a sample consisting predominantly of adolescents [35]. Another study reported a higher rate of self-reported depressive symptoms in school-age children [36]. Interestingly, in a Dutch study, young adolescents with CHD reported less rule- breaking behavior than healthy controls [27]. Except for one study with a low methodological rating [34], all other studies were of moderate or good methodological quality.

\section{Risk factors for psychological malfunctioning}

The type of heart defect was unrelated to proxy-reported psychological functioning in most studies [26,29,35,37-39]. Accordingly, neither the presence of cyanosis $[20,23]$, nor cardiac function [18] was associated with self-reported 
psychological adjustment. In contrast, two studies found an effect of the type of heart defect on behavior. One could show that parents of children with ventricular septal defect reported more behavioral problems than parents of children with atrioseptal defect or pulmonary stenosis [27]. Another study demonstrated that only children with a hypoplastic left heart syndrome had psychological maladjustment compared to those with a transposition of the great arteries [28]. In line with these findings is that parents of children with cyanosis [23], or with reduced physical capacity [19], reported psychological maladjustment following surgery in their child. Correspondingly, children in need for further surgical intervention were more likely to suffer from co-morbid psychiatric illness than those without this prospect according to parental reports [18].

Surgery-related deep hypothermic circulatory arrest was associated with poorer proxy-reported psychological outcome compared to low or full flow bypass procedures $[32,39]$. Additionally, the duration of deep hypothermic circulatory arrest correlated with the degree of proxyreported psychological difficulties in one study [24], yet not in another study [40]. Peri- and postoperative cardiovascular insufficiency related to poorer proxy-reported behavioral outcome [24]. Older age at surgery and a higher number of surgeries were related to reduced proxyreported psychological functioning in one study [39]. Another study did not find support for such a relationship [40].

Individual characteristics such as postoperative developmental delay were consistently related to child psychological maladjustment in parental reports [24,32,35,37]. Yet, self-reported psychological adjustment was not associated with measures of intelligence $[18,35]$. Sex differences in overall psychological adjustment were not observed $[37,39]$.

Family characteristics early parental distress was related to proxy-reported behavioral difficulties in children with operated transposition of the great arteries [31] and maternal anxiety was related to self-reported fear in the child as well as to proxy-reported behavioral maladjustment [23]. In addition, poor parental control skills, single parent status, high maternal worry about the child and increased levels of maternal psychological symptoms were all related to poorer behavioral adjustment in children with a variety of CHD [20]. Interestingly, one study demonstrated that early social support for the family was unrelated to longterm psychological adjustment in the operated child [31].

\section{Quality of life}

Additional file 2 [see Additional file 2] gives an overview of the results of the 12 studies reporting postoperative
QoL. In four of these studies QoL in children with operated CHD was comparable to that in normative samples according to proxy- $[28,41]$, self- [24] or combined reports [42]. These studies received quality ratings between 5 and 9 points. Another study observed a normal proxy-reported QoL in more than 90\% of their sample based on cut-off values, yet this result was not based on inferential statistics [43]. One study observed a better selfreported QoL in a large sample of children with transposition of the great arteries undergoing surgery compared to healthy norms [44]. In this sample, corrective surgery included the atrial as well as the arterial switch operation. Children with arterial switch operation showed a better functioning compared to those with atrial switch. In contrast, four studies reported an impaired QoL in many selfand most proxy-reported dimensions [45-48]. Methodological quality in these studies varied between 5 and 9 points. Two studies did not report overall QoL, but examined the agreement between parental and self rated QoL [49] and the influence of two ventricle versus single ventricle physiology [50].

Two studies compared QoL of children with CHD with that of children with other chronic illnesses. In one study children with CHD after surgery experienced a better proxy-reported QoL [47], yet the opposite was found in another study [41].

As QoL is a multidimensional construct various subdimensions were evaluated across studies. A direct comparison between studies, however, cannot be made as different measures and concepts of QoL have been used (see Table 1).

\section{Risk factors for impaired quality of life}

The type of heart defect did not relate to QoL in a heterogeneous diagnostic sample [48] and in a small sample of children with transposition of the great arteries or hypoplastic left heart syndrome [28]. However, two studies found a lower QoL in children with more complex malformations $[44,47]$. In a sample of children with single ventricle anatomy only few cardiac-specific factors were found to be related to QoL [46].

Considering surgery related factors cardiopulmonary bypass duration was inversely related to QoL in three studies $[24,44,45]$ but not in other studies [43,46]. Also, conflicting data exist on the effects of duration of circulatory arrest $[41,43,44]$ or the number of cardiac surgeries $[41,46,47]$. No effects on QoL were found for vital organ support technique [41], cooling temperature [44], or age at surgery $[43,46]$. Postoperative complications, length of hospital stay and current need for cardiac medication were negatively related to QoL in two studies $[45,46]$. 
Individual characteristics sociodemographic factors such as sex $[41,48]$ or socioeconomic status $[41,45,47]$ were not associated with QoL in children. However, Landolt et al. [45] found a higher self-reported QoL in boys compared to girls. Older age at follow up assessment was associated with a better QoL in two studies $[47,48]$. Also, a higher IQ was related to better psychosocial QoL in one study [41].

Family characteristics children of parents who remained unemployed due to the child's health condition or children of families with a low income experienced a lower QoL than controls [46]. Finally, adverse family relationship [45] and parental stress at follow up [43] were both found to be negatively related to the psychosocial dimensions of QoL.

\section{Discussion}

This review is the first to systematically summarize the literature of the last 18 years on psychological adjustment and quality of life of children and adolescents with CHD following cardiopulmonary bypass surgery. Moreover, potential risk factors for psychological maladjustment and impaired quality of life are reported.

\section{Proxy-reported long-term outcome}

Studies assessing the incidence of psychiatric diagnoses, although few, as well as studies investigating the rates of clinically significant behavioral symptoms have demonstrated that a considerable proportion of these children experience psychological maladjustment according to their parents. The observed proportion of children with a psychiatric diagnosis $[18,19]$ is comparable to children with other chronic illnesses, who have a two-fold higher risk than children in the general population $[51,52]$. Likewise, significantly more children with operated defects displayed behavior outside a normative range $[21,22,24,30,35]$. In the same line, studies assessing mean levels of psychological functioning found significantly more psychological difficulties in operated children compared to controls $[21,23,24,33,35,37,40]$. As an exception, parents of children with surgically corrected transposition of the great arteries consistently reported good or even better psychological adjustment [31,32,41] than controls. This good outcome may be due to the excellent prospect of correcting this malformation by means of arterial switch operation. A lower rate of genetic disorders in this subgroup of patients may also contribute to this favorable outcome. As the latter findings originated from the same institution and are partly based on overlapping samples, they need to be confirmed by other groups.

Interestingly, teachers judged the behavior and functioning of children with CHD similar to that of control children $[21,22]$. Although these findings need replication, they point out the discrepancy between parental reports and teacher reports. The results indicate that the children's difficulties are less apparent within the schooling context. This may be due to the fact that children are reported to show predominantly internalizing problems, which are less likely to be detected by teachers than by parents. Alternatively, this result may highlight the importance of the negative influence of parental anxieties with regard to their subjective perception of their children.

\section{Self-reported long-term outcome}

To date, there are only few studies that assessed selfreported psychological adjustment in children after cardiopulmonary bypass surgery. Thus, available results do not allow for a final conclusion but provide further directions of research. Three studies did not find differences in selfreports of children with operated heart defects compared to a reference group, thus contrasting proxy reports $[18,23,34]$. The divergence between parents and their children (and teachers), the so-called cross-informant variance, has frequently been reported across different clinical samples [53]. It may reflect differing, yet equally important, realities [54] and highlights the need for outcome assessments using multiple informants. Only two studies observed a significant degree of self-reported behavioral difficulties $[35,36]$. Since the study by Utens et al. comprised a large proportion of adolescent cases, this finding does not contradict other results that are based on selfreports in children. Yet, it may indicate a decline in psychological adjustment associated with the onset of puberty and the increasing academic demands. Clearly, more research is needed to confirm these findings.

\section{Quality of life}

Current data suggest that children with CHD undergoing cardiopulmonary bypass surgery may be faced with an impaired QoL at follow-up [45-48]. Impairments are more frequently reported by parents than by the patients themselves. Notably, in 4 of the 12 reviewed studies, a normal QoL was found. Children with operated transposition of the great arteries may be overrepresented in the reviewed studies as most samples comprised children with this defect only $[24,41,44]$ or included a subsample of these children $[43,48]$. Thus, findings may not be applicable to the remaining population of children with CHD.

\section{Risk factors for long-term outcome}

To date, there is insufficient and conflicting data to attribute long-term outcome to the various risk factors assessed. As only few studies evaluated the same risk factors, findings are preliminary and demand replication. Moreover, the evaluation of risk factors often did not adhere to strict statistical standards, i.e., by adjusting for confounding variables by means of multivariate analysis. 
The cardiac diagnosis does not seem to be a particular risk factor for psychological maladjustment after cardiopulmonary bypass surgery. This has been demonstrated in numerous studies across different ages $[26,29,35,37$ $39,41,45]$. Nevertheless, physical correlates of the heart defects (such as cardiac insufficiency mandating cardiac medications or arrhythmias during follow-up) or other physical problems such as pulmonary problems may lead to reduced proxy-reported psychological adjustment and QoL $[19,23,45-47]$. Such a relationship was not detected for child self-reports $[18,23]$.

While surgery itself may pose a risk for long-term outcome, current research has attempted to assess the effects of various organ support techniques, duration of surgery $[24,32,39-41,44,45]$ and length of hospital stay [45]. However, potential confounders such as depth of hypothermia or postoperative complications must be carefully controlled for before a conclusion can be derived. Likewise more data are needed addressing the conflicting current findings.

Developmental delay is a child-specific risk factor that has consistently been found to relate to proxy-reported psychological maladjustment following heart surgery $[24,32,35,37,41]$. Thus, parents of children with language difficulties or cognitive delay reported more psychological difficulties in their children. In contrast, this association was not found for self-reported psychological adjustment. Other risk factors such as sex, education or socioeconomic status have rarely been investigated.

Finally, the parents of children with operated heart defects themselves may play an important role with regard to the child's long-term psychological adjustment $[23,31]$ and quality of life $[43,45,46]$. However, more research is needed to further evaluate the role of parental adjustment for the long-term outcome and QoL in their children. Also, the causal rather than the correlational nature of this relationship warrants empirical support.

\section{Limitations and implications for future research}

With regard to the methodology of the reviewed studies, several limitations were identified. Only four out of 35 studies were found to be of high methodological quality according to a self-developed rating system. All but one study [31] applied a cross-sectional or retrospective design. This approach does not allow to describe the dynamic course of psychological adjustment or QoL in relation to surgery. Neither does the use of normative data or healthy control groups suffice to causally attribute group differences to the surgical procedure itself; they may be associated with the chronic disease itself $[41,47]$. Thus, a control group design should account for $a$ ) the effect of a high-risk surgical intervention, and $b$ ) the effect of living with CHD. Even if these standards are met, results still need to be discussed in the light of potential confounding, i.e., less severe illness in controls.

In this systematic review, we did not include studies that only focused on children with chromosomal anomalies. However, we did not find a study that only addressed this subgroup. The reviewed studies typically excluded patients with chromosomal anomalies and non-cardiac comorbidities. Because cardiac defects frequently result from chromosomal disorders and because neurological disability is one of the major risk factors associated with cardiopulmonary bypass surgery, the exclusion of such patients may have biased findings towards better outcome. Thus, less restrictive exclusion criteria and the systematic use of subgroup analysis will allow to determine QoL and psychological adjustment in these children.

Other limitations relate to the operationalization of outcome variables. As most studies assessed psychological adjustment by means of the Child Behavior Checklist [12] well-known shortcomings of the scale within the context of chronic disease must be addressed [55]. While this instrument has been validated for a psychiatric population, its suitability for chronically ill children is unclear. The optimal assessment instrument should allow for a clear distinction between symptoms primarily associated with the disease and those associated with consequences of the disease validated for the target population. To the best of our knowledge, no such scale exists for the assessment of psychological adjustment in children with chronic diseases. In contrast, such progress has been made with regard to the psychometric assessment of quality of life. Recently, the PedsQL [56] has been supplemented with a cardiac module [57], and is currently under validation. In addition, a large US research group has published the Pediatric Quality of Life Inventory (PCQLI), which is a disease specific QoL measure for children with CHD [50]. The PCQLI has patient and parent-proxy forms, covers a wide age range and showed very promising data in the multi-center validation study. Certainly, future studies on QoL in children with CHD should incorporate these new disease specific measures.

\section{Conclusion}

This review demonstrated that a significant proportion of children with CHD experience psychological maladjustment following cardiopulmonary bypass surgery. Children with more severe heart defects, or those in need of future surgical interventions and children with neurodevelopmental impairment are at particular risk for maladjustment. The QoL of these children appears also to be affected, particular with regard to parental reports. However, the literature on this important outcome is still emerging and disease-specific instruments have just been 
published. Importantly, parental well-being seems to be related to psychological adjustment in these children. This calls for an integrated approach to family support, taking the child's individual needs into account as well as the needs of the parents.

\section{Competing interests}

The authors declare that they have no competing interests.

\section{Authors' contributions}

BL and MAL participated in the selection and review of studies and the writing of the manuscript. SH participated in the selection and review of studies and drafted the manuscript. JEF and UB participated in the interpretation of findings and critically reviewed the manuscript. All authors read and approved the final manuscript.

\section{Additional material}

\section{Additional File 1}

Table presenting psychological adjustment in children and adolescents with CHD after CPB surgery grouped by major outcome variables and methodological quality. The table gives an overview of studies assessing psychological adjustment in children with congenital heart defects after bypass surgery, studies are grouped by major outcome variables and methodological quality.

Click here for file

[http://www.biomedcentral.com/content/supplementary/1471-

2431-9-6-S1.xls]

\section{Additional File 2}

Table presenting quality of life in children and adolescents with CHD after CPB surgery grouped by major outcome variables and methodological quality. The table gives an overview of studies assessing quality of life in children with congenital heart defects after bypass surgery, studies are grouped by major outcome variables and methodological quality. Click here for file

[http://www.biomedcentral.com/content/supplementary/14712431-9-6-S2.xls]

\section{Acknowledgements}

This research was funded by a grant from the Foundation Mercator Switzerland.

\section{References}

I. Botto LD, Correa A, Erickson JD: Racial and temporal variations in the prevalence of heart defects. Pediatrics 200I, 107:E32.

2. Pradat $P$, Francannet $C$, Harris JA, Robert $E$ : The epidemiology of cardiovascular defects, part I: a study based on data from three large registries of congenital malformations. Pediatr Cardiol 2003, 24: 195-221.

3. Marino BS, Bird GL, Wernovsky G: Diagnosis and management of the newborn with suspected congenital heart disease. Clin Perinatol 200I, 28:91-136.

4. Boneva RS, Botto LD, Moore CA, Yang Q, Correa A, Erickson JD: Mortality associated with congenital heart defects in the United States: trends and racial disparities, 1979-1997. Circulation 200I, 103:2376-238I.
5. Allen SW, Gauvreau K, Bloom BT, Jenkins KJ: Evidence-based referral results in significantly reduced mortality after congenital heart surgery. Pediatrics 2003, I | 2:24-28.

6. Meberg A, Otterstad JE, Froland G, Lindberg H, Sorland SJ: Outcome of congenital heart defects-a population-based study. Acta Paediatr 2000, 89: I344-I35I.

7. Bove T, Francois K, De Groote K, Suys B, De Wolf D, Verhaaren H, Matthys D, Moerman A, Poelaert J, Vanhaesebroeck P, Van Nooten $\mathrm{G}$ : Outcome analysis of major cardiac operations in low weight neonates. Ann Thorac Surg 2004, 78:181-187.

8. Oppido G, Napoleone CP, Formigari R, Gabbieri D, Pacini D, Frascaroli G, Gargiulo G: Outcome of cardiac surgery in low birth weight and premature infants. Eur J Cardiothorac Surg 2004, 26:44-53.

9. Murphy GJ, Angelini GD: Side effects of cardiopulmonary bypass: what is the reality? J Card Surg 2004, 19:48I-488.

10. Limperopoulos C, Majnemer A, Shevell MI, Rohlicek C, Rosenblatt B, Tchervenkov C, Darwish HZ: Predictors of developmental disabilities after open heart surgery in young children with congenital heart defects. J Pediatr 2002, 141:51-58.

II. Bellinger DC, Bernstein JH, Kirkwood MW, Rappaport LA, Newburger JW: Visual-spatial skills in children after open-heart surgery. J Dev Behav Pediatr 2003, 24:169-I79.

12. Achenbach TM, Edelbrock C: Manual for the Child Behavior Checklist and revised child behavior profile. University of Vermont, Burlington, VT; 1983.

13. Koot HM: The study of quality of life: Concepts and methods. In Quality of life in child and adolescent illness Edited by: Koot HM, Wallander JL. Hove: Brunner-Routledge; 2001.

14. Fritsch J, Winter UJ, Kaemmerer H, Hilger HH: Cardiopulmonary capacity of patients with congenital heart defects in childhood, adolescence and adulthood. Z Kardiol 1994, 83(Suppl 3): $131-139$.

15. Casey FA, Craig BG, Mulholland HC: Quality of life in surgically palliated complex congenital heart disease. Arch Dis Child I994, 70:382-386.

16. Ternestedt BM, Wall K, Oddsson H, Riesenfeld T, Groth I, Schollin J: Quality of life 20 and 30 years after surgery in patients operated on for tetralogy of Fallot and for atrial septal defect. Pediatr Cardiol 200I, 22: I28-132.

17. APA: Diagnostic and Statistical Manual of Mental Disorders. forth edition. Washington D.C: American Psychiatric Association; 1994.

18. Alden B, Gilljam T, Gillberg C: Long-term psychological outcome of children after surgery for transposition of the great arteries. Acta Paediatr 1998, 87:405-410.

19. Bjornstad PG, Spurkland I, Lindberg HL: The impact of severe congenital heart disease on physical and psychosocial functioning in adolescents. Cardiol Young 1995, 5:56-62.

20. McCusker CG, Doherty NN, Molloy B, Casey F, Rooney N, Mulholland C, Sands A, Craig B, Stewart M: Determinants of neuropsychological and behavioural outcomes in early childhood survivors of congenital heart disease. Arch Dis Child 2007, 92:|37-|4|.

21. Oates RK, Turnbull JA, Simpson JM, Cartmill TB: Parent and teacher perceptions of child behaviour following cardiac surgery. Acta Paediatr 1994, 83: 1303-1307.

22. Wright M, Nolan T: Impact of cyanotic heart disease on school performance. Arch Dis Child 1994, 71:64-70.

23. Gupta S, Giuffre RM, Crawford S, Waters J: Covert fears, anxiety and depression in congenital heart disease. Cardiol Young 1998, 8:491-499.

24. Hovels-Gurich HH, Konrad K, Wiesner M, Minkenberg R, HerpertzDahlmann B, Messmer BJ, Von Bernuth G: Long term behavioural outcome after neonatal arterial switch operation for transposition of the great arteries. Arch Dis Child 2002, 87:506-5I0.

25. Mahle WT, Clancy RR, Moss EM, Gerdes M, Jobes DR, Wernovsky G: Neurodevelopmental outcome and life style assessment in school-aged and adolescent children with hypoplastic left heart syndrome. Pediatrics 2000, 105:1082-1089.

26. Miatton M, De Wolf D, François K, Thiery E, Vingerhoets G: Intellectual, neuropsychological, and behavioral functioning in children with tetralogy of Fallot. Journal of Thoracic and Cardiovascular Surgery 2007, 133:449-455.

27. Spijkerboer AW, Utens EMWJ, Bogers AJJC, Verhulst FC, Helbing WA: Long-term behavioural and emotional problems in four 
cardiac diagnostic groups of children and adolescents after invasive treatment for congenital heart disease. International Journal of Cardiology 2008, I 25:66-73.

28. Brosig CL, Mussatto K, Kuhn EM, Tweddell JS: Psychosocial outcomes for preschool children and families after surgery for complex congenital heart disease. Pediatric Cardiology 2007, 28:255-262.

29. Goldberg CS, Schwartz EM, Brunberg JA, Mosca RS, Bove EL, Schork MA, Stetz SP, Cheatham JP, Kulik T]: Neurodevelopmental outcome of patients after the Fontan operation: A comparison between children with hypoplastic left heart syndrome and other functional single ventricle lesions. I Pediatr 2000, I 37:646-652.

30. Ellerbeck KA, Smith LS, Holden WE, McMenamin SC, Badawi MA Brenner JI, Kan JS, Hyman SL: Neurodevelopmental outcomes in children surviving d-transposition of the great arteries. J Dev Behav Pediatr 1998, 1 9:335-341.

31. Visconti KJ, Saudino KJ, Rappaport LA, Newburger JW, Bellinger DC Influence of parental stress and social support on the behavioral adjustment of children with transposition of the great arteries. J Dev Behav Pediatr 2002, 23:314-32I.

32. Bellinger DC, Rappaport LA, Wypij D, Wernovsky G, Newburger JW: Patterns of developmental dysfunction after surgery dur ing infancy to correct transposition of the great arteries. J Dev Behav Pediatr 1997, I 8:75-83.

33. Karl TR, Hall S, Ford G, Kelly EA, Brizard CP, Mee RB, Weintraub RG Cochrane AD, Glidden D: Arterial switch with full-flow cardiopulmonary bypass and limited circulatory arrest: neurodevelopmental outcome. J Thorac Cardiovasc Surg 2004, I 27:2 I 3-222.

34. Salzer-Muhar $U$, Herle $M$, Floquet $P$, Freilinger M, Greber-Platzer S, Haller A, Leixnering W, Marx M, Wurst E, Schlemmer M: Self-concept in male and female adolescents with congenital heart disease. Clin Pediatr (Phila) 2002, 4 I: I7-24.

35. Utens EM, Verhulst FC, Meijboom FJ, Duivenvoorden HJ, Erdman RA Bos E, Roelandt JT, Hess J: Behavioural and emotional problems in children and adolescents with congenital heart disease. Psychol Med 1993, 23:415-424.

36. Miatton M, De Wolf D, François K, Thiery E, Vingerhoets G: Behavior and self-perception in children with a surgically corrected congenital heart disease. I Dev Behav Pediatr 2007, 28:294-30 I.

37. DeMaso DR, Beardslee WR, Silbert AR, Fyler DC: Psychological functioning in children with cyanotic heart defects. J Dev Behav Pediatr 1990, I I :289-294.

38. Spijkerboer AW, Utens EMWJ, Bogers AJJC, Helbing WA, Verhulst FC: A historical comparison of long-term behavioral and emotional outcomes in children and adolescents after invasive treatment for congenital heart disease. Journal of Pediatric Surgery 2008, 43:534-539.

39. Utens EM, Verhulst FC, Duivenvoorden HJ, Meijboom FJ, Erdman RA Hess ]: Prediction of behavioral and emotional problems in children and adolescents with operated congenital heart disease. European Heart Journal 1998, 19:801-807.

40. Kern JH, Hinton VJ, Nereo NE, Hayes Cl, Gersony WM: Early developmental outcome after the Norwood procedure for hypoplastic left heart syndrome. Pediatrics 1998 I02: I148-1152.

41. Dunbar-Masterson C, Wypij D, Bellinger DC, Rappaport LA, Baker $A L$, Jonas RA, Newburger JW: General health status of children with D-transposition of the great arteries after the arterial switch operation. Circulation 2001, I 04: I38-142.

42. Ekman-Joelsson BM, Berntsson L, Sunnegardh J: Quality of life in children with pulmonary atresia and intact ventricular septum. Cardiol Young 2004, I4:6I5-62I.

43. Majnemer A, Limperopoulos C, Shevell MI, Rohlicek C, Rosenblatt B Tchervenkov $C$ : Health and well being of children with congenital cardiac malformations, and their families, following open-heart surgery. Cardiol Young 2006, 16:157-164.

44. Culbert EL, Ashburn DA, Cullen-Dean G, Joseph JA, Williams WG, Blackstone $\mathrm{EH}, \mathrm{McC}$ rindle BW: Quality of life of children after repair of transposition of the great arteries. Circulation 2003, 1 08:857-862.

45. Landolt MA, Valsangiacomo Buechel ER, Latal B: Health-related quality of life in children and adolescents after open-heart surgery. J Pediatr 2008, I 52:349-355.

46. McCrindle BW, Williams RV, Mitchell PD, Hsu DT, Paridon SM, Atz MA, Li JS, Newburger JW: Relationship of patient and medical characteristics to health status in children and adolescents after the Fontan procedure. Circulation 2006, I | 3: I I 23- I I 29.

47. Mussatto K, Tweddell J: Quality of life following surgery for congenital cardiac malformations in neonates and infants. Cardiol Young 2005, I 5(Suppl): I 74- I 78.

48. Spijkerboer AW, Utens E, de Koning WB, Bogers AJ, Helbing WA Verhulst FC: Health-related quality of life in children and adolescents after invasive treatment for congenital heart disease. Qual Life Res 2006, I 5:663-673.

49. Goldbeck L, Melches J: Quality of life in families of children with congenital heart disease. Quality of Life Research 2005, 14:1915-1924.

50. Marino BS, Shera D, Wernowsky G, Tomlinson RS, Aguirre A, Gallagher M, Lee A, Cho CJ, Stern W, Davis L, et al.: The development of the pediatric cardiac quality of life inventory: a quality of life measure for children and adolescents with heart disease. Quality of Life Research 2008, 17:613-626.

5I. Lavigne JV, Faier-Routman J: Psychological adjustment to pediatric physical disorders: a meta-analytic review. J Pediatr Psychol 1992, I 7:133-157.

52. Costello EJ, Egger $\mathrm{H}$, Angold A: I0-year research update review: the epidemiology of child and adolescent psychiatric disorders: I. Methods and public health burden. J Am Acad Child Adolesc Psychiatry 2005, 44:972-986.

53. Varni JW, Katy ER, Colegrove R, Dolgin MJ: Adjustment of children with newly diagnosed cancer: Cross-informant variance. Journal of Psychosocial Oncology 1995, 13:23-38

54. Jokovic A, Locker D, Guyatt G: How well do parents know their children? Implications for proxy reporting of child healthrelated quality of life. Qual Life Res 2004, I 3:I297-I307.

55. Perrin EC, Stein RE, Drotar D: Cautions in using the Child Behavior Checklist: observations based on research about children with a chronic illness. J Pediatr Psychol I99|, I 6:4 I I-42 I.

56. Varni JW, Burwinkle TM, Seid M, Skarr D: The PedsQL 4.0 as a pediatric population health measure: feasibility, reliability, and validity. Ambul Pediatr 2003, 3:329-34I.

57. Uzark K, Jones K, Burwinkle TM, Varni JW: The Pediatric Quality of Life Inventory (TM) in children with heart disease. Progress in Pediatric Cardiology 2003, I 8: |4 | - 48.

\section{Pre-publication history}

The pre-publication history for this paper can be accessed here:

http://www.biomedcentral.com/1471-2431/9/6/prepub

Publish with Biomed Central and every scientist can read your work free of charge

"BioMed Central will be the most significant development for disseminating the results of biomedical research in our lifetime. "

Sir Paul Nurse, Cancer Research UK

Your research papers will be:

- available free of charge to the entire biomedical community

- peer reviewed and published immediately upon acceptance

- cited in PubMed and archived on PubMed Central

- yours - you keep the copyright

Submit your manuscript here:

http://www.biomedcentral.com/info/publishing_adv.asp
BioMedcentral 